physiology. Chicago: Year Book Medical Publishers, 1962.

VALENSTEIN, E. S., \& WEBER, M. L. Potentiation of insulin coma by saccharin. Journal of Comparative \& Physiological Psychology, 1965, 60, 443-446.

VAN ITALLIE, T. B., \& HASHIM, S. A. Biochemical concomitants of hunger and satiety in man. American Journal of Clinical Nutrition, $1960,8,587-594$.

\section{NOTES}

1. Supported by a research grant awarded to $N$. R. Remley by the Texas Christian University Research Foundation (Grant No. FR-07106-01 BMPS 6892).

2. Walker, D. W., \& Remley, N. R. The relationships among percentage body weight loss, circulating free fatty acids, and consummatory behavior in rats, in preparation.

3. Sigma Chemical Co. Technical Bulletin No. 14.

\title{
Behavioral selectivity in tropical fish
}

H. A. CROSS, ' L. J. LAUX, J. C. WRIGHT, V. J. PEZOLDT, J. J. LOWENSTEIN, T. D. VINCENT, and N.W. KING, Wittenberg University, Springfield, Ohio 45501

Three strains of tropical fish belonging to the same genus, Xiphophorus, were given the opportunity to view stimulus fish of the same or differing strains in a free-choice preference situation. The test $S$ s spent significantly more time with their own kind, indicating a behavioral selectivity which is consistent with previously observed biological selectivity.

Although tropical platyfishes and swordtails belong to the same genus, Xiphophorus, and will interbreed when restricted, they never, or almost never, cohabit in their natural habitat (Clark, Aronson, \& Gordon, 1964). Kallman (n.d.) reports that not a single natural hybrid has ever been discovered. This has been the case even when more than 50,000 fish have been collected together. The question must naturally arise as to the mechanisms which support this selectivity. A number of possible factors have been elaborated, and include: different preferences with respect to ecological niche; finer differentiation within the micro environment; small differences in the shape and size of the female genital papillae; and possible differences in behavior patterns (Kallman, n.d.).

This study was designed to find out if the sexual selectivity observed by the biologist could be translated into a behavioral discrimination in a situation in which a fish was afforded an opportunity to justapose himself alongside a stimulus $S$ of his own strain or fish of the same genus but of different strain. The free-choice preference method (Sackett, 1966; Cross, Halcomb, \& Matter, 1967) was employed throughout. If the previously described exclusion is apparent in the behavioral situation, refined tests become possible. In short, a methodology will then be available which, potentially at least, could provide evidence concerning the relative effect upon preference behavior of a number of physical and behavioral variables, including: coloration, odor, physical shape and size, bodily orientation, and movement.

\section{EXPERIMENT 1} Method

The test (T) Ss were 36 tropical fish: 12 Xiphophorus maculatus (Gold crescent moon); 12 Xiphophorus maculatus (Red calico moon); and 12 Xiphophorus helleri (Green swordtail). Half of the Ss of each strain were male and half were female. Three males and three females of each strain were housed in individual 3-gal aquaria, making a total of 18 "isolated" fish. The remaining 18 fish were "social" Ss and were housed as follows: one fish of each strain in a 3-gal tank, such that half of the tanks contained one male and two females, and half contained one female and two males. Two isolated Ss, one female crescent and one male swordtail, died during the testing, and the subsequent statistical analysis involved only 34 fish. In addition to the T Ss, there were 12 male fish, 4 of each strain, who served as stimulus or object $(\mathrm{O}) \mathrm{Ss}$. These O Ss were housed socially, with each strain represented once in the home tank.

There were two identical test tanks, each consisting of a 10-gal aquarium measuring $201 / 2 \times 101 / 2 \times 11 \frac{3 / 4}{4}$ in. The test tanks were divided in half by length with wire screen. One side was further divided into four equal compartments, each measuring $5 \times 4 \%$ in. These smaller compartments served as stimulus areas and housed the male 0 fieh. The other side comprised the T S's compartment and measured $191 / 4 \times 4 \%$ in. The stimulus compartments were divided by opaque glass which extended through the screen $2 \%$ in. in to the T S's area. Balsa-wood inserts completely covered the interior of the $10 \frac{1}{2} \times 11 \frac{3}{4}$ in. sides, but the front side was open to $\mathrm{E}$ for easy observation of $\mathrm{T}$ fish. The water of all tanks was maintained between 72 and $78 \operatorname{deg}$ F. A fluorescent tube was affixed 8 in. above the stimulus compartment of both test tanks. Each apparatus was accompanied by a recording console, consisting of four electric clocks that were activated by a four-position selector switch, manually operated by $E$.

On a given test, a male of each strain was selected from the $O$ Ss according to a random schedule. The three $O$ Ss were placed in one of the four stimulus compartments according to a random, but balanced, schedule. One compartment was empty and was the "start" compartment. A given set of $O$ Ss served nine $T$ Ss on a given day. All 120 Ss were used each day of testing. A trial started immediately when a T $S$ was placed in the test tank opposite the empty or "start" compartment and continued for $8 \mathrm{~min}$. The measure of stimulus preference used was the total time a T $S$ was in each stimulus area. The $S$ was judged in a given area when two-thirds of its body was within the compartment.

The experimental design was a five-factor analysis of variance, involving sex, strain, and isolation condition of the T Ss as nesting variables and strain of the $O$ Ss and blocks as repeated-measure variables. Thus, a given $T$ $S$ represented one of three strains, was male or female, and was isolated or social in his home tank. Test trials were continued over a 3-week period with all T Ss tested the first 4 evenings of each week. After 4 test days, one block, there was a 3-day period of no testing. This continued until all T Ss had completed 12 trials.

\section{Results and Discussion}

An unequal-n analysis of variance, using total time scores for each block, was completed. Table 1 shows the mean daily time scores (in seconds), collapsed over blocks, that the test strains spent with the various 0 strains. An $\alpha$ level of .025 was imposed, with the result that the expected interaction of $\mathrm{T}$ by $\mathrm{O} \mathrm{Ss}$ was significant $(F=3.51, d f=4 / 44, p<.025)$. The T Ss by $\mathrm{OSs}$ by Block interaction was also significant $(F=2.49, \mathrm{df}=8 / 88, \mathrm{p}<.025)$ but did not present a clear picture. No other $F$ tests we re significant.

The results were somewhat as predicted, but only the calico Ss consistently selected against Ss of the "outgroup." Experiment 1 gave an opportunity to observe a number of things. It became apparent that the fish kept in isolation were not being strictly deprived

Table 1

Mean Daily Total Time (Seconds)

\begin{tabular}{lccr}
\hline & \multicolumn{3}{c}{ Object Fish } \\
\cline { 2 - 4 } Test Fish & Crescent & Calico & Swordtails \\
\hline Crescent & 105.68 & 128.12 & 99.54 \\
Calico & 111.75 & 120.52 & 104.31 \\
Swordtails & 136.77 & 105.36 & 138.76 \\
\hline
\end{tabular}


of visual contact with their own kind since they could observe their images as they were reflected in the glass of both the home and test tanks. In fact, Ss often spent time in vertical ascent and descent while orienting to the tank side. It was also noted that when Ss were first placed into the tank, they showed some "trauma" and spent long periods in the start compartment before any swimming. Finally, the uneven deprivation of the isolated Ss, i.e., $72 \mathrm{~h}$ on Day 1 of a given block and $24 \mathrm{~h}$ on subsequent days, presented a problem. Experiment 2 was designed to give attention to these limitations.

\section{EXPERIMENT 2 \\ Method}

The $T$ Ss were identical in number and kind to those employed in Experiment 1, while the $O$ Ss were identical in kind but reduced to six. Some Ss had served in Experiment 1, but a large number had not.

All fish were separated by sex and placed in one of the two original test tanks for a 24-day habituation period. One male of each strain was assigned to a given test tank as an O S. These O Ss lived in this tank throughout all subsequent testing. The remaining 18 males and 18 females were placed into isolation and social tanks as in Experiment 1 . This time, however, all tanks, including the test ones, were completely enclosed on the inner side with 3/8-in. plywood to prevent Ss from viewing their images. The test tanks were equipped with overhead mirrors to allow $E$ to see the movement of T Ss. Several other changes were introduced. The $\mathrm{O} S \mathrm{~S}$ were placed in a given compartment according to a random schedule, but in order to avoid disrupting these fish, they were kept in the same compartment for 2 test days before being rotated to another compartment. Extreme care was given to the handling of T Ss which were placed in the test tank opposite the "start" compartment, allowed $5 \mathrm{~min}$ to adjust, and were then timed for a period of $15 \mathrm{~min}$. The darkness of the test tanks necessitated the lowering of the fluorescent tubes to within $1 \mathrm{in}$. of the water. The experimental design was a four-factor analysis of variance, with sex, strain, and isolation of the T Ss as nesting variables and the strain of the $\mathrm{OSs}$ as a repeated-measure variable. The experiment continued for 24 consecutive days, with three isolated and three social Ss, one of each strain, tested on each day. All Ss were run once every 6 days for a total of four trials each. The isolated Ss, then, had been socially deprived $144 \mathrm{~h}$ prior to each trial.

\section{Results and Discussion}

Three T Ss (an isolated crescent, a social calico, and a social swordtail) died during the experiment; but, since two trials had been recorded from two of these Ss and three from the other $S$, their mean scores were used in the analysis of variance involving total mean "viewing" times. Table 2 shows the mean total times (in seconds). The interaction, Strain of T Ss by Strain of O Ss, was significant $(F=10.73$, $\mathrm{df}=4 / 48, \mathrm{p}<.001)$. Multiple comparisons involving the three means within each test strain were done using the Scheffé procedure (Hays, 1963). Of the six comparisons, only one was not significant $(\alpha=.025)$; the swordtails did not significantly select against the calico Ss. These results indicate an overwhelming tendency for Ss of a given strain to choose members of their own strain in preference to fish of other strains. Only one additional F ratio, Isolation Condition by Sex, was significant $(F=8.44, \mathrm{df}=1 / 24, \mathrm{p}<.01)$. The social females were overall more "gregarious" than were the social males, with means of $244.26 \mathrm{sec}$ and $203.30 \mathrm{sec}$, respectively. In the isolation condition, the sociability of the sexes was reversed, with a male mean of $232.37 \mathrm{sec}$ and a female mean of $202.26 \mathrm{sec}$.
Table 2

Mean Total Times (Seconds)

\begin{tabular}{lcrr}
\hline & \multicolumn{3}{c}{ Object Fish } \\
\cline { 2 - 4 } Test Fish & Crescent & Calico & Swordtails \\
\hline Crescent & 319.75 & 183.42 & 172.83 \\
Calico & 170.42 & 332.16 & 148.66 \\
Swordtails & 165.75 & 223.33 & 268.66 \\
\hline
\end{tabular}

The behavioral analog to the reported biological selectivity has been observed, and a methodology for further study is available. Little more can be said. The specific physical characteristics and/or behavior patterns which account for this "ingroup" activity remain obscure until further research. One methodological limitation should be noted. The "social" Ss of this experiment, while not deprived of contact with othét fish, were isolated from Ss of their own strain. Failure to observe additional isolation-condition effects could be attributable to this.

\section{REFERENCES}

CLARK, E., ARONSON, L. E., \& GORDON, M. Mating behavior patterns in two sympatric species of Xiphophorin fishes: Their inheritance and significance in sexual isolation. Bulletin of the American Museum of Natural History, 1954, 103, 135-226.

CROSS, H. A., HALCOMB, C. G., \& MATTER, W. W. Imprinting or exposure learning in rats given early auditory stimulation. Psychonomic Science, 1967, 7, 233-234.

HAYS, W. L. Statistics for psychologists. New York: Holt, Rinehart, \& Winston, 1963.

KALLMAN, K. Platys and swordtails. New York: The Pet Library, n.d.

SACKETT, G. P. Development of preference for differentially complex patterns by infant monkeys. Psychonomic Science, 1966, 6, 441-442.

\section{NOTE}

1. Now at Colorado State University, Fort Collins, Colo. 80521. 